\title{
EL ESTATUS NEPANTLA DEL DARIYA CEUTÍ: ENTRE LA BASTARDÍA Y LA INFERIORIZACIÓN
}

\author{
Hamed ABDEL-LAH ALI*
}

\begin{abstract}
«La identidad es siempre una pausa transitoria en un proceso de identificación. Los grupos sociales y los individuos acumulan, a lo largo del tiempo, diferentes identidades y en cada momento pueden disponer de varias identidades complementarias y contradictorias. De este "stock" identitario, una de las identidades asume, según las circunstancias, la primacía». (Santos 2010: 37)
\end{abstract}

BIBLID [1133-8571] 26 (2019) 08.1-14.

Resumen: Despojarse de algo tan emblemáticamente identitario como puede ser la lengua de los grupos minoritarios, tras sucumbir ante la gran «maquinaria asimiladora» del grupo mayoritario hegemónico, requiere de un relato seudocientífico que sobredimensione el valor de la lengua dominante e infravalore la subalternada. Un relato manipulador cuyo alcance afecta a las actitudes lingüísticas infiriendo negativamente en la percepción, valoración y comportamiento externo de las personas hacia la lengua marginada como el dariya ceutí. La realidad polifónica y liminal de Ceuta requiere de una nueva gramática que supere el binarismo simplista y deficitario que - desde la verticalidad- sigue privilegiando a una lengua y excluyendo a las otras. De ahí nuestra predilección por categorías producidas desde, con y para el Sur como el transculturalismo y el nepantlismo.

Palabras clave: Transculturalismo, Nepantlismo, Identidad, Mestizaje, Frontera, Dariya, Comunidad, Exclusión.

Abstract: «The nepantla status of Dariya in Ceuta: between bastardy and inferiorization». To relinquish something so symbolically linked to the identity as the minorities groups' language, succumbing to the great "assimilator machine" of the hegemonic and majority group, requires a pseudo-scientific account capable of overrating the dominant language's value and undervaluing the subordinated one. A manipulative narrative affecting linguistic behaviors, influencing negatively on the perception, valuation and external behavior of the people to the marginalized language, such as

* Profesor de Secundaria de Lengua Castellana y Literatura. E-mail: benenyeli7@gmail.com.

AAM, 26 (2019) XXX-XXX 
the Ceuti Darija. The polyphonic and liminal reality of Ceuta needs a new grammar that could get over the simplistic and deficient binarism that, by means of a vertical approach, still grants privileges to one language and excludes others. These facts explain our predilection for categories produced from, with and for the South, like «transculturalism» and «nepantilism».

Key words: Multiculturalism, Nepantlism, Identity, Mixing, Border, Darija, Community, Exclusion.

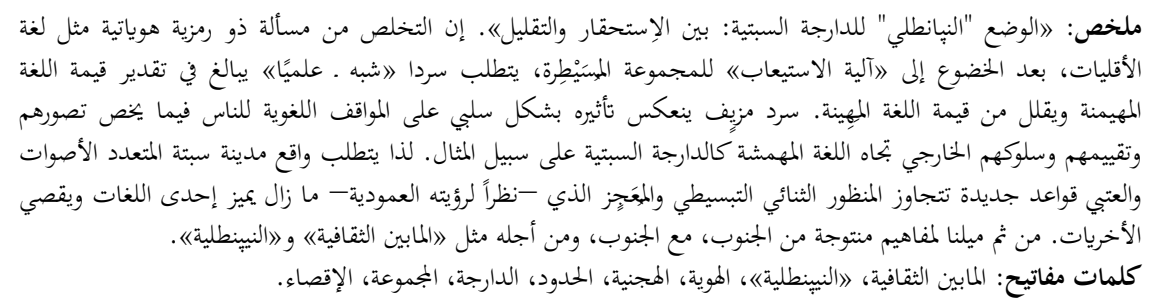

\section{Introducción}

La sociedad multicultural ceutí ha sufrido en las cuatro últimas décadas una involución en lo que respecta a la convivencia entre las diferentes comunidades que la componen, teniendo como resultado la aparición de tres tipos de comunidades: una mayorizada, otra minoritaria (ambas fortaleza y excluyentes) y la tercera minorizada (ameba). A nivel lingüístico, el dariya ceutí es una lengua fronteriza, mestiza y transcultural, que está rechazada no ya solo por el grupo mayoritario hegemónico, sino por una pequeña parte de sus propios hablantes, que por efecto «Pigmalión» y por su arrogante etnocentrismo parecido en intensidad al de la mayoría castizo cristiana occidentalistabastardiza su lengua materna, idealizando el árabe fusha (literal) en pro de una ilusoria adscripción a la «umma» islámica.

La lengua, además de ser uno de los rasgos más peculiares con los que se suele caracterizar a los grupos étnicos, es el eje vertebrador sobre el que éstos construyen sus respectivas identidades que -siendo tan diversas, heterogéneas y complejas- están inmersas en un proceso gradual y continuo de construcción, deconstrucción y reconstrucción, esto es transculturación.

Las lenguas, al igual y unísono que las identidades, padecen un tanto de lo mismo, ya que no son objetos acabados, esenciales o primarios, sino más bien: 
[...] objetos secundarios", procesos y no resultados, que se construyen a través de complejos entramados sociopolíticos y culturales. Estas lenguas y estas identidades siempre tienen algo detrás (un Estado, una nación sin estado, una historia, una voluntad de futuro, una magnitud o cierto número de hablantes) que las hacen distintas y desiguales... Por eso las lenguas se sitúan en espacios de interacción, en juegos de fuerza y poder. (Esteban 2007: 17)

De ahí que, además de su función comunicativa, la lengua dentro de ese juego interrelacional suele ser usada diferentemente en función del tipo de relaciones y necesidades. Sin embrago de manera esquemática se podrían resaltar tres tipos de roles:

$>\quad$ La lengua materna ${ }^{(1)}$, familiar, grupal: adquirida normalmente en la etapa de socialización primaria. De entorno local, suele representar las tradiciones y cultura populares.

$>$ La lengua como instrumento de intercomunicación socio-laboral. De ámbito estatal, es usada en la administración e institución públicas.

$>\quad$ La lengua de interconexión global con proyección internacional.

\section{El imperialismo lingüístico glotofágico-homogeneizador}

Despojarse de algo tan emblemáticamente identitario como puede ser la lengua de cualquier comunidad de habla, habiendo ejercido toda resistencia necesaria y vital para no sucumbir ante la gran «maquinaria asimiladora» hegemónica del grupo mayoritario, además de precisar un periodo que abarque unas cuantas generaciones, requiere sobre todo de un relato que sobredimensione el valor de la lengua dominante e infravalore la subalternada. Relato defendido a ultranza - disfrazado de cientificidad pragmática, la del bien común- primero por los diferentes dispositivos del aparato antes señalado, luego por la teoría del framing $^{(2)}$, del efecto Pigmalión y la profecía auto-cumplida, a

(1) Pese a la dificultad encontrada a la hora de intentar definir el concepto de «lengua materna», se comparte con esta autora su definición, lengua materna es aquella: «que una persona relaciona directamente con su cultura de origen, independientemente de quién haya sido la persona o el colectivo que la haya transmitido» (Rivera 2001: 1).

(2) Derivado de frame en inglés que significa encuadre o marco, sería «un proceso en el que se seleccionan algunos aspectos de la realidad, a los que les otorgará un mayor énfasis o importancia, de manera que se define el problema, se diagnostican sus causas, se sugieren juicios morales y se proponen soluciones y conductas apropiadas a seguir». Aplicado al ámbito informativo, la noticia es descrita «como una ventana cuyo marco delimita la realidad a la que se tiene acceso, limitando la percepción de otra realidad diferente y centrando la 
las diferente comunidades que conforman el resto de la sociedad, cuya diversidad refleja a su vez diferentemente el grado de aceptación / percepción de tal injusta desigualdad: narcisamente valorada por los endógenos, sumisamente aceptada por los exógenos.

\subsection{Las actitudes lingüísticas}

A fin de intentar comprender «la manera como el contexto social influye en los pensamientos, sentimientos, comportamientos, etc., de los individuos», Allport (Janés 2006: 122), uno de los fundamentos básicos en los que la Teoría de Acción Social centra su interés es el elemento mediador que vincula el sujeto actor con la situación en la que actúa; es decir, en la interpretación que el primero hace de lo segundo.

Pese a la dificultad de una observación directa y medición rigurosa, «sólo podemos deducir que alguien tiene actitudes mediante sus palabras y acciones» (Hernández 2004: 29); por ello, «[...] la actitud lingüística es una manifestación de la actitud social de los individuos, distinguida por centrarse y referirse específicamente tanto a la lengua como al uso que de ella se hace en sociedad, y al hablar de lengua incluimos cualquier tipo de variedad lingüística» (Moreno 1998: 179).

Las actitudes son "constructos" (Hernández 2004: 29), «estructuras» hipotéticas y disposiciones adquiridas con las que las personas valoran positiva o negativamente «un objeto, persona, suceso o situación» (Carulla 2006: 122), infiriendo en su comportamiento externo «en consonancia» con su valoración.

Como factores de índole psicosocial que infieren significativamente en el comportamiento de los hablantes, tales actitudes ${ }^{(3)}$ se interiorizan, se fomentan y se reproducen mediante el contacto y la interacción sociolingüística. Por ello se ha de subrayar la fuerte relación que hay entre lengua e identidad, ya que su importancia es de tal magnitud que conlleva confundir lo sentido por un hablante con la valoración hecha sobre su lengua.

atención en ese fragmento específico. Como consecuencia de estos procesos, algunos aspectos de la realidad percibida a través de las noticias serán más prominentes que otros». Ambas citas son paráfrasis de Ardèvol (2015).

(3) Las actitudes cambian conforme al contexto sociocultural, lingüístico y educativo del sujeto, así como a su género y edad. 


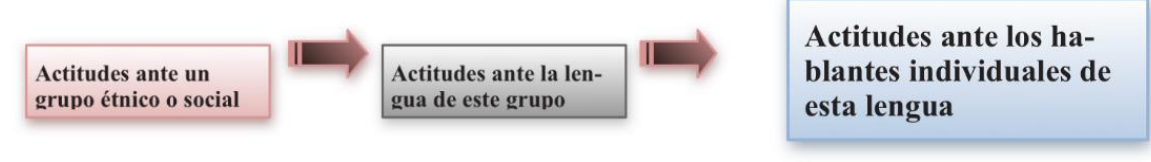

Figura1: Esquema que representa la formación de actitudes. Fuente: Appel \& Muysken (1986).

Además, otros ${ }^{(4)}$ estudios realizados muestran que las actitudes solamente pueden ser negativas o positivas, que la neutralidad es más bien una ausencia de actitud y que los prejuicios lingüísticos son sobre todo estereotipos sobre las comunidades que hablan tales lenguas, cuyo prestigio está asociado a su estatus socioeconómico. Investigadores de IULA3 ${ }^{(5)}$ indican que:

\footnotetext{
«Una lengua vale lo que vale el grupo que la habla. Una lengua tiene poder de atracción si los individuos que la hablan tienen poder adquisitivo, están bien situados socialmente y tienen capacidad de influir en la sociedad. Si se renuncia a hablar una lengua es porque se asocia a los grupos sociales más desfavorecidos, al retraso socioeconómico y a un nivel educativo bajo».
}

Es una obviedad afirmar que en casi todas las actuales sociedades globalizadas, la diversidad abarca ya todos los ámbitos generando con ello conflictos, producidos por el contacto entre lo mayoritario y lo minoritario, con el único fin de defender o acaparar más espacio hegemónico; es decir, competir o compartir( ${ }^{(6)}$. El resultado ha sido tan evidente como natural: «a más globalización más localización; a más homogeneidad más heterogeneidad» ${ }^{(7)}$.

En Ceuta, cada comunidad cultural tiene su propia lengua, pero todos hablan el español. Sin embargo, en el ámbito familiar y grupal, usan sus respectivas lenguas maternas produciéndose con ello un contacto en el que se compite y comparte espacios. Los idiomas más hablados son el español y el dariya ${ }^{(8)}$, cuya relación trasciende lo puramente lingüístico para plasmarse en

\footnotetext{
(4) En Calvo Shadid, 2014.

(5) Institut de Linguística Aplicada de la Universitat Pompeu Fabra. En Idem.,146.

(6) Ídem. p.3. Esteban aclara que las «tres funciones pueden entrar en contacto, simbiosis o solapamiento».

(7) Ídem, p.16.

(8) Dariya, árabe dialectal, coloquial, vulgar o ceutí preferimos utilizar el primer término y el último sin entrar en distinciones peyorativas, cuyo fundamento -tanto para los que lo
} 
forma de «manifestación de la identidad social» (Rivera 2012: 99). Bárbara Herrero (2013: 17) por su parte, considera que: «En Ceuta la intersección entre la cultura arabo-islámica, la cultura y la lengua locales,
además de la existente a su vez entre éstas, y la lengua-cultura española, es un hecho que no
sólo se encuentra latente, sino que es un elemento constitutivo y definitorio de la identidad de
la ciudad en las que estas tres esferas colisionan, se interpenetran y simbiotizan en un espacio
muy reducido y concreto».

En este reducido espacio fronterizo, el árabe, el dariya, el amazigh (en menor grado), el andaluz y el castellano configuran la identidad arabomusulmana ceutí, cuyo idioma «se encuentra doblemente estigmatizado» ${ }^{(9)}$, tanto por monolingües cristiano-peninsulares, como por marroquíes araboparlantes ${ }^{(10)}$; ya que para ambos, tal comunidad ni habla bien una cosa ni la otra $^{(11)}$. Reacción comprensible viniendo de posicionamientos etnocentristas puritanos que ven el mestizaje, degradación y vileza; con en el consecuente efecto en la autopercepción negativa reflejada en el fenómeno no menos importante denominado diglosia ${ }^{(12)}$, que ha generado en los hablantes del dariya ceutí un complejo «juego de lealtades» (Herrero 2013: 63).

En lo que respecta a su relación con el árabe fusha vinculado al ámbito religioso, así como al literario, su sentimiento de inferioridad es debido a la dualidad moral real / ideal; esto es, el cómo se habla (ser real, dariya) / cómo se debería hacer (ser ideal, fusha). Por lo que hablar árabe sería «hablar

consideran como mero dialecto oral o una degradación del árabe culto- no es otro que el de su prejuicio etnocentrista con fines político- económicos.

(9) Rivera, op.cit., 71

(10) Resaltar que incluso dentro de la comunidad dariya-parlante ceutí, bien por defensa de un quimérico e idealizado panarabismo islamista, o por auto percepción negativa se menosprecia e infravalora su propia lengua materna. Posible efecto Pigmalión.

(11) De entre los casi 86 mil habitantes establecidos en Ceuta, este colectivo representa aproximadamente el $45 \%$ de la población. Es realmente llamativo que el Delegado del Gobierno que representa a todos los ceutíes descalifique la lengua que habla la mitad de sus representados como «ni siquiera es un idioma», en El Faro de Ceuta [03 de enero del 2013].

(12) Fenómeno sociolingüístico que hace referencia a la cohabitación simultánea de dos idiomas de desigual prestigio y consideración que son socialmente jerarquizados; donde el idioma A de carácter formal es usado en ámbitos institucionales y el B marginalizado es reducido a situaciones comunicativas menos formales. 
musulmán» ${ }^{(13)} y$ adscribirse a la comunidad arabo-islámica internacional «la umma», mientras que hacerlo en español equivaldría a «hablar en cristiano». En relación a esta última, también es considerada como variedad de prestigio, puesto que su competencia lingüística suele ser «inferior»a la de sus hablantes «nativos»; y si su lengua es además oficialmente invisibilizada, busca una solución in between.

Al igual que muchos hablantes de «medias lenguas» (Moreno Fernández 2006: 9) -típicas de contextos fronterizos-, el colectivo dariya-parlante ceutí(14), refuerza su cohesión ya que está en proceso de construcción identitaria - ¿y cuándo se deja de estarlo?- manifestada en el complejo fenómeno de codeswitching con el que intenta erigir su propia identidad:

«[...] el ceutí musulmán se siente un trozo de tierra desligado de su todo, que adquiere identidad por diferencia y en ocasiones por su indiferencia respecto a la alteridad análoga [...] síndrome de isla, muestra complejo por su "mal árabe", "mal español” y "mal marroquí"” (Herrero 2013: 66).

\subsection{Sociolingüística de las ausencias}

La grave repercusión que los defectos metodológicos de algunos especialistas del lenguaje pueden acarrear en la percepción tanto de las variedades lingüísticas genéticamente parecidas a la lengua hegemónica, del resto de las lenguas orales y escritas con las que haya coexistido, así como de las lenguas criollas autóctonas y migradas, suele ser de tal magnitud que sólo los hablantes de éstas son conscientes de ello. Dado que, como se dijo anteriormente, infravalorar su lengua es hacer lo mismo con su identidad, sus sentimientos, su auto-percepción, su memoria, su visión del mundo y su autoestima. Y de la misma forma que no se puede -ni se debe- jerarquizar parcial o totalmente, tanto las culturas, las etnias como sus espiritualidades, tampoco ha de hacerse con los idiomas, ya que ninguna lengua es mejor que otra. Las asimetrías distan de aspectos puramente lingüísticos: tienen su origen en coyunturas históricas y socioculturales.

(13) Las dos expresiones son de uso coloquial, pero cuyo trasfondo sería interesante analizar, así como el de identificación lengua / religión.

(14) Preferimos utilizar los acrónimos (AMAD) y (CAPC) para referirnos a ambas comunidades ceutíes: la Arabo-Musulmana-Amazigh-Dariyaparlante y la Cristiano-Agnóstica-PeninsularCastellanoparlante. 
A nivel local, tras analizar las actitudes lingüísticas de los y las participantes en los grupos de discusión ${ }^{(15)}$ categorizadas en cinco puntos extrapolados de la Sociología de las Ausencias de Santos ${ }^{(16)}$, hemos podido apreciar el alcance que las manipulaciones de aquel dispositivo seudocientífico han tenido sobre la población ceutí analizada.

1. Lengua artificial y cultivada / lengua natural.

2. Linealidad del paradigma evolucionista.

3. Macro escala pan-hispanista / arabista: nacionalismo lingüístico.

4. Productividad global ganancialmente cuantificada.

5. La jerarquización supremacista de las lenguas medias canibalizadas.

Resaltamos que en lo referente a las actitudes, éstas sólo pueden ser negativas o positivas; por lo que, partiendo de la división tripartita de las comunidades antes aludidas, podríamos subdividirlas en dos subgrupos: los dariyófobos representados por las dos comunidades fortaleza (la "mayorizada" y la minoritaria) y sus oponentes dariyófilos (encarnados por la comunidad «minorizada» ameba). De manera resumida, los defensores -adscritos o no al colectivo (AMAD) - de esta comunidad abogan por un tercer espacio transcultural, libre de binarismos simplistas, en el que -desde la horizontalidad simétrica- todas las lenguas tuvieran cabida, donde su lengua materna (por su

(15) Padres y Madres del alumnado dariyaparlante, Profesores de religión islámica, Voluntarios ONG, Asociación Cult.1, $1^{\circ}$ Partido político, Asociación Cult.2, 2 Partido político y Entidad religiosa.

(16) Para Boaventura de Sousa Santos, hay cinco formas de invisibilización de las que se sirve el razonamiento mono-cultural, etnocentrista e indolente para auto-legitimarse y desechar el resto de las alternativas por no considerarlas válidas ni creíbles.

\begin{tabular}{|l|l|l|}
\hline Categorías & Conocimiento hegemonizado & Conocimiento silenciado \\
\hline Cientificismo & Saber riguroso. & Ignorante, popular e inculto \\
\hline Linealidad & Tiempo, progreso, desarrollo & Tradicional, obsoleto y residual. \\
\hline Escala & Macro dominante: global & Micro: particular, local e inviable. \\
\hline Productividad & Ganancia maximizada & Improductivo \\
\hline Jerarquía & Superioridad legítima & Inferioridad natural e insuperable. \\
\hline
\end{tabular}


mestizaje) es un buen reflejo de ello como se verá después de analizar las actitudes de los otros dos colectivos que - pese a su antagonismo- convergen en su rechazo radical a la «bastarda» lengua de sus paisanos.

Las dos primeras comunidades, desde un puritanismo fortaleza y excluyente, infravaloran con agresividad el dariya ceutí, ya que para ambos no es más que un registro oral, bajo, inculto, improductivo y meramente tribal, desviado del árabe y bastardo, que por no ser, ni es una cosa (español), ni la otra (árabe). Una bastardía que perjudica seriamente a los y las hablantes de ambas lenguas hegemónicas (pese a que la árabe apenas tenga presencia real en Ceuta), dado que no sólo obstaculiza su desarrollo educativo normal en la lengua oficial, sino que - para el subgrupo minoritario- degenera y contamina su «musulmaneidad».

\section{2. «زWa l’colega! Pillart wah.d 25 gramos, ¡Máshaa L.lah!»(17)}

Cierta vez ${ }^{(18)}$, el poeta uruguayo Eduardo Galeano dijo que «el mundo está organizado de tal manera que tenemos derecho de elegir la salsa con la que seremos comidos». Y ya que la perspectiva deficitaria con la que hasta el momento se ha intentado aprehender el dariya ceutí, fomentando su inferiorización, consideramos que como herramienta analítica, esta «salsa» no nos es válida por su inoperancia.

Esta realidad polifónica, heteroglósica y liminal, producida por un contacto cultural, lingüístico, religioso, civilizacional y en una zona fronteriza como la ceutí, requiere de una nueva gramática. Dado que con las categorías

(17) Hace aproximadamente dos años y medio, saliendo de una mezquita, un joven ceutí (AMAD) recibe una llamada, tras un breve silencio, le escuchamos enunciar eufóricamente la siguiente frase que transcribimos literalmente: «¡Wa l'colega! Pillart wah.d 25 gramos, ¡Máshaa L.lah!», frase que decidimos tomarla como paradigma que refleja fielmente la identidad actual del ceutí (AMAD). La traducción vendría a significar algo parecido a lo siguiente: «iEh colega! He pillado unos 25 gramos (de hachís) ¡Alabado sea el Señor!». En lo que respecta a la significado literal de la exclamación ;Máshaa L.lah! es: «esto es lo que Dios ha querido / dispuesto».

(18) En una charla en Italia, Eduardo Galeano, en relación al orden político internacional dijo: «Yo escuché a un cocinero que reunió a las gallinas, a los gansos, a los pavos, a los faisanes y a los patos. El cocinero les preguntaba con qué salsa querían ser comidas. Una de las aves, creo que era una humilde gallina, dijo: "nosotras no queremos ser comidas de ninguna manera". Y el cocinero aclaró: "eso está fuera de la cuestión”. Me pareció interesante esa reunión porque es una metáfora del mundo. El mundo está organizado de tal manera que tenemos derecho de elegir la salsa con la que seremos comidos» (Arias 2007). 
binarias, esencialistas, deficitarias, simplistas y tradicionales producidas en el Norte hegemónico, que suele observar al Sur desde la verticalidad monocultural, sólo se podrá (re)producir y mantener el statu quo, privilegiando a una parte y excluyendo a la otra. De ahí nuestra inclinación por categorías como la siguiente producidas desde, con y para el Sur $^{(19)}$

\subsection{El nepantlismo ${ }^{(20)}$}

Estar nepantla y nepantlismo sería según Troncoso (2011: 380):

«[...] aquel proceso de transformación inconcluso, en que los indígenas, y después los mestizos, se encontraban posteriormente a la conquista, ya que permanecían "en medio" de la cultura española y la indígena, no eran "ni lo uno, ni lo otro", se encontraban transitando de una fase a otra, en un estadio intermedio "entre" dos polos, "en medio" de un camino trazado, de un proceso de transición que quedaría truncado».

Los contactos culturales forzosamente inducidos e impuestos suelen provocar en la parte más débil una especie de «transformación social involuntaria» (León-Portilla 1976: 21) parecida al nepantlismo; de ahí que este autor considere oportuno elevar este concepto a categoría científica debido a su aplicabilidad en otros contextos similares, estableciéndolo

(19) Entendido el sur como: «[...] una metáfora del sufrimiento humano causado por el capitalismo y el colonialismo a nivel global y de la resistencia para superarlo o minimizarlo [...] Es un Sur que existe también en el Norte global, en la forma de poblaciones excluidas, silenciadas y marginadas» (Santos 2011: 34)

(20) El municipio Nepantla se encuentra en el extremo sureste del Estado de México. Como vocablo apareció por primera vez traducido al castellano en 1547, en el diccionario del padre Andrés de Olmos (2002: 152) como sinónimo de «en medio» o «entre»; sin embargo, fue el dominico andaluz fray Diego Durán, quien en 1581 lo utilizó connotativamente como equivalente de «estar neutros». En su obra, el padre Durán describe que tras enterarse de que un joven indio organizó una costosa fiesta a la que asistió todo el pueblo y en la que presuntamente se llevaron a cabo rituales indígenas, le pidió explicaciones; y el joven increpado, le rogó al fraile no alarmarse ya que aún estaban nepantla; aunque el padre pudo deducir que la expresión denotaba «estar en medio», le instó al joven ser más explícito, a lo que éste le respondió que: «como no estaban aún bien arraigados en la fe [...] que ni bien acudían a la una ley ni a la otra, por mejor decir que creían en Dios y que juntamente acudían a sus costumbres antiguas y del demonio» (Durán 1984: 237). 
«[...] como "la palabra clave de la tragedia de un pueblo", es decir, el término que ilustra el proceso, continuo, sin interrupciones, de agresión e imposición cultural, y al mismo tiempo de exclusión social y económica" sufrido por los indígenas mexicanos por más de quinientos años. Tiende un puente entre lo experimentado por los indios del siglo XVI con los de la actualidad, constituyendo un continuum atroz» (Troncoso 2011: 383).

La operatividad del término, según León-Portilla valdría también para describir la situación padecida en la actualidad por los chicanos ${ }^{(21)}$ «sometidos a procesos de aculturación en ocasiones violentos»; por ello, en vez de sincretismo o mestizaje, esta categoría reflejaría con más acierto y precisión esa compleja realidad tanto a nivel sincrónico como diacrónicamente; además, en consonancia con Salvador Velasco (1999: 4), al hablar de nepantlismo:

«[...] no debe pensarse en un armonioso sincretismo cultural. Debe entenderse la idea de estar nepantla como un desplazamiento entre diferentes campos culturales (Mesoamérica y Europa); es un estado dinámico y cambiante, una reconstrucción de fronteras culturales e ideológicas; es un espacio de conflicto y escisión, de ruptura y continuidad».

\section{Conclusión}

La frase «iWa l'colega! Pillart wah.d 25 gramos, ¡Máshaa L·lah!», tomada como paradigma, refleja la mezcla transcultural del castellano, el andaluz, el dariya, el árabe, el amazigh, el ámbito delictivo, el registro o argot juvenil y el religioso. Por ello hemos recurrido a conceptos del Sur epistemológico y periférico echando mano a nociones como el transculturalismo, la criollización, el nepantlismo.

Al fin y al cabo, los primeros aluden al proceso que, mediante el «toma y daca», dos -o más- entidades en contacto se construyen, se destruyen y se reconstruyen en algo nuevo: una pausa transitoria en la que -de ese «stock» identitario- se asume temporalmente una de las tantas identidades que la componen. No tiene por qué ser una u otra cosa; puede ser ambas o ninguna. Mientras que el último, se refiere al resultado y al producto. De ahí que o se

(21) La discriminación padecida por esta comunidad es doble: por un lado, pese a ser ciudadanos estadounidenses, en EEUU se les denomina «chicanos» por ser de origen mexicano; y por otro, en México, peyorativamente se les llama «pochos» por adoptar costumbres y hábitos yanquis. Algo muy similar a lo padecido por la comunidad arabo-musulmana-bereberdariyaparlante ceutí, expresado en grupos de discusión llevados a cabo en nuestra investigación. 
percibe positivamente como una fuente de riqueza que está nepantla; o desde un «chovinismo lingüístico» prejuzgarlo negativamente por su blasfema «bastardía» y por ser «hijo de la chingada».

Consideramos que la criollización es -como otros tantos- un mecanismo ancestral del que echan mano los hablantes de las lenguas que entran en contacto cuando lo necesitan para afrontar las exigencias demandadas por el entorno socio-geográfico compartido. Si los hablantes del dariya ceutí y a quienes les gustaría serlo, han tenido que recurrir a este mecanismo ancestral, primero para acomodarse a su entorno, lo han hecho sobre todo para crear ese espacio intersticial y poder habitar la frontera sin tener que sufrir los márgenes excluyentes.

Para ello se pretende promover su merecida valoración y reconocimiento, no tanto como rasgo exclusivamente propio de la comunidad (AMAD) ceutí, sino de todas las que habitan este insignificante espacio parroquial, cuya trascendencia histórica tuvo efectos globalizadores ${ }^{(22)}$ en tiempos pasados, y que obviamente se pueden mejorar partiendo «de abajo hacia arriba».

\section{BIBLIOGRAFÍA}

ABREU, A. I. Alberto. 2015. «Framing o teoría del encuadre en comunicación. Orígenes, desarrollo y panorama actual en España». En: Revista Latina de Comunicación Social 70, pp. 423-450.

(22) «La globalización comenzó en Ceuta». De este modo fue titulado un artículo que se publicó en el periódico El Mundo, el 20 de marzo de 2015, en el que se resaltaba la trascendencia global de un evento sucedido seis siglos atrás en un minúsculo municipio, cuyo alcance contribuyó significativamente al «despertar de la Europa Moderna». Un acontecimiento que según el Doctor en Historia Antonio Carmona Portillo «introdujo a Ceuta en la Europa Moderna». Para más información, véase «La entrada de Ceuta en Europa. 1415. El legado portugués», conferencia pronunciada en la Casa de Ceuta de Cádiz el día 21 de octubre de 2015 en el transcurso de la la XV Jornada Cultural); de ahí que haya de ser considerado como «una fecha histórica», «simbólica» y un «punto de inflexión» según palabras del Cronista Oficial de la Ciudad José Luis Gómez Barceló, en El Pueblo de Ceuta, el 21 de agosto de 2015.

AAM, 26 (2019) XXX-XXX 
ARIAS, Diego. 2007. Plan Decenal De Educación: Razones para dudar de sus alcances. En 〈http://viva.org.co/cajavirtual/svc0060/articulo05.pdf> [20 de enero de 2019].

CALVO SHADID, Annette. 2014. «Análisis de actitudes positivas y negativas hacia el habla costarricense». Revista Káñina 38, 2, pp.143-159.

CARULLA JANÉS, Judit. 2006. «Las actitudes hacia las lenguas y el aprendizaje lingüístico». En: Revista Interuniversitaria de Formación del Profesorado 20 (56), pp. 117-132.

DURÁN, Diego. 1984. Historia de las Indias de Nueva España. Vol. I. México, Porrúa.

ESTEBAN GUITART, Moisés, NADAL, Josep María, \& VILA, Ignasi. 2007. «El papel de la lengua en la construcción de la identidad: un estudio cualitativo con una muestra multicultural». En: Glossa 2, 2, pp. 1-20.

HERNÁNDEZ-CAMPOY, Juan Manuel. 2004. «El fenómeno de las actitudes y su medición en sociolingüística». En Tonos digital: Revista electrónica de estudios filológicos 8, pp. 29-56.

HERRERO MUÑOZ-COBO, Bárbara. 2013. El árabe ceutí. Un código mixto reflejo de una identidad mestiza. Ceuta, Instituto de Estudios Ceutíes.

LEÓN-PORTILLA, Miguel. 1962. «Nepantla. La palabra clave de la tragedia de un pueblo». En: Periódico Excélsior, 23 de enero, México, D.F. (1976). México, Culturas en peligro, FCE.

MORENO-FERNÁNDEZ, Francisco. 1998. Principios de sociolingüística y sociología del lenguaje. Barcelona, Ariel.

--- 2006. «Medias lenguas e identidad». En III Congreso Internacional de la Lengua Española, Rosario. En: Centro Virtual Cervantes. Consultado el: <https://cvc.cervantes.es/obref/congresos/rosario/ponencias/aspectos/more no f.htm> [04 junio de 2018]

RIVERA, Verónica. 2006. «Importancia y valoración sociolingüística del Darija en el contexto de la Educación Secundaria pública en Ceuta». En: Revista electrónica de estudios filológicos 12, pp. 1-21.

--_ 2011. «La lengua materna como elemento afectivo y base para el aprendizaje». En: Revista electrónica aula intercultural. En: <http://www.aulaintercultural.org/IMG/pdf/lenguamaterna-vrivera.pdf $>$ [01 de marzo de 2018]

--- 2012. El contacto de lenguas en Ceuta. Ceuta, Instituto de Estudios Ceutíes. 
DE SOUSA SANTOS, Boaventura. 2009. Una epistemología del Sur: la reinvención del conocimiento y emancipación social. México, Siglo XXI CLACSO.

--- 2010. «Desigualdad, exclusión y globalización: hacia la construcción multicultural de la igualdad y la diferencia». En: Igualdad y no discriminación. El reto de la diversidad. Danilo Caicedo Tapia y Angélica Porras Velasco (eds.). Quito, Ministerio de Justicia, Derechos Humanos y Culto, pp. 3-51.

<https://eg.uc.pt/bitstream/10316/41728/1/Desigualdad\%2C\%20exclusi\% C3\%B3n\%20y\%20globalizaci\%C3\%B3n.pdf> [21 de octubre de 2019].

TRONCOSO PÉREZ, Ramón. 2011. «Nepantla, una aproximación al término». En: Tierras prometidas. De la colonia a la independencia. Castany, Bernat $\&$ al. (eds.). Barcelona, Centro para la Edición de los Clásicos EspañolesUAB, pp.375-398.

VELAZCO, Salvador. 1999. « Reconstrucciones historiográficas y etnicidades emergentes en el México colonial: Fernando de Alva Ixtlilxochitl, Diego Muñoz Camargo y Hernando Alvarado Tezozomoc». Mesoamérica, 20 (38), pp. 1-32. 